\title{
An Empirical study on the Relationship between Social Responsibility and Financing Cost of family firm
}

\author{
Wang Haifei ${ }^{1, a_{*}} \quad$ Zhangyu ${ }^{2, b}$ \\ Accounting School, Jilin University of Finance and Economics, Changchun City, Jilin Province, \\ China \\ Email: wanghaifei20080919@126.com
}

Keywords: Family firm, Social responsibility, Cost of financing

\begin{abstract}
As the basic elements of the society, family enterprises value their social benefits more than their economic benefits. Based on Chinese 517 listed family enterprises which are the research sample of this paper, it empirically test the relationship of the family enterprise social responsibility and corporate financing cost, the study results show that: with the improvement of corporate social responsibility of the family, it will gradually reduce the cost of financing. Compared with large family enterprises, small family enterprises can more easily control the financing cost by developing their own social responsibility.
\end{abstract}

\section{Introduction}

Family business means that the main shares and capital of the enterprise are concentrated in a certain family, and the starring managers and leaders in the enterprise are composed of internal personnel of the family. From the perspective of power, if a company belongs to a family business, the management rights and ownership of the enterprise are controlled by one or more families ${ }^{[1]}$.

The concept of corporate social responsibility has a long history, and the social responsibility defined from the perspective of stakeholders is widely recognized. That is, enterprises should bear the corresponding legal responsibilities to the major internal shareholders and use the production and sales activities to obtain economic benefits. Responsibilities of stakeholders such as consumers and employees ${ }^{[2]}$. To some extent, the process of fulfilling corporate social responsibility can be seen as a process of contributing to society. Carrol divides the level of corporate social responsibility into the following table:

Table 1 Class of corporate social responsibility

\begin{tabular}{ll}
\hline Class & Type of social responsibility \\
\hline One & Economic responsibility \\
Two & Law responsibility \\
Three & Moral responsibility \\
Four & Charity responsibility \\
\hline
\end{tabular}

\section{Theoretical analysis and research hypothesis}

\subsection{The importance of family business social responsibility}

The section headings are in boldface capital and lowercase letters. Second level headings are typed as part of the succeeding paragraph (like the subsection heading of this paragraph).From an essential point of view, the importance of family business social responsibility is mainly reflected in the following aspects:

First, the nature of the business. From the perspective of the nature of the enterprise, the management rights of the family business are controlled by one family or multiple families. Therefore, when the family business has problems in fulfilling social responsibility, this problem affects the external image of the enterprise while people The impression of the family will also change accordingly. This feature reinforces the importance of social responsibility in family businesses ${ }^{[3]}$. 
Second, the particularity of managers and employees. Compared with ordinary enterprises, family business managers are mostly family members, and family members also occupy a certain proportion; while the managers and employees of ordinary enterprises are characterized by diversity. Based on the particularity of the composition of the team, it is more necessary for the family business to reflect the fairness of the company by fulfilling its social responsibility.

Third, market competition. The market environment with competitive characteristics has brought certain pressure on the operation and development of major enterprises. If the family business is a food production enterprise, its commitment to consumer rights and responsibility (one of the evaluation criteria of social responsibility) will indirectly affect its market competitiveness. For example, if the family business better fulfills the rights and interests of consumers' food safety, the consumer will form a good impression on the family business. When the consumer once again generates the demand for purchasing similar products, the family enterprise can meet its needs. At the time, consumers will regard the family business as the first choice for consumption ${ }^{[4]}$.

Fourth, financing costs. Capital is an important guarantee for the operation and development of a company. When a family enterprise cannot meet the requirements for the development, production and sales of a project or product, it will obtain certain funds from outside investors (creditors) by means of financing activities. Factors such as the level of family business social responsibility, scale, and asset-liability ratio are necessary factors for creditors to make decision-making assessments.

Fifth, corporate reputation. The reputation effect is one of the important ways for companies to achieve sustainable development goals. To a certain extent, there is a very close relationship between the brand of the company and the reputation of the company. When the reputation of the family business is affected, for example, the family business publicizes a large amount of funds for a public welfare activity, but if it is confirmed that there is a problem of false report later, and the degree of recognition of the reputation of the family business by consumers will also change somewhat ${ }^{[5]}$.

\subsection{The impact of family business social responsibility on financing costs}

Social responsibility is one of the basic components of a company's reputation. From this perspective, the social responsibility of the family business can be regarded as the reputation of the company in the outside world. Through the analysis of corporate reputation theory and related data, it can be found that the better the external reputation of the family business, the lower the difficulty of achieving the financing purpose without considering other influencing factors. Combined with the actual operation of major enterprises in China, the impact of family business social responsibility on financing costs is mainly concentrated in the following aspects:

First, moral reputation. The moral reputation of a family business is generated through its social responsibility. If a family business gains a high level of social responsibility in the course of business development, its moral reputation will also increase accordingly. For creditors, in the process of evaluating the family business, they will fully consider the role of moral reputation in the market share of the company, and thus the impact on financing costs (interest parameters) ${ }^{[6]}$.

Second, the ability to respond to risks. Investor investment decisions are based on the following principles: low investment risk principles. From an essential point of view, investors hope that the financing activities of the family business can be successfully completed, and the products developed and produced can be sold in large quantities. The low risk of financing activities means that investors' investment behavior will not cause economic losses; the principle of high risk response capability. If the risk of the family business financing activity itself is high, but the risk hardness capability of the family business can fully withstand the risk problem, investors are also willing to invest in it, and the interest parameters set for the family business are relatively small.

From the perspective of operational risk, the advantages of large-scale family-owned enterprises in the transparency of business information provide a good way for investors to evaluate the business capability of enterprises; small family enterprises are obviously weak in this respect. In this case, improving the degree of social responsibility development is a key way for small family businesses to prove their own capabilities and reduce risks. As the level of social responsibility of small family 
businesses continues to increase, the cost of financing activities will decrease accordingly. Based on this, hypothesis one is proposed:

H1: Compared with large enterprises, it is relatively difficult for small and medium-sized family enterprises to achieve the goal of reducing the cost of financing by improving social responsibility performance.

The development of family business social responsibility will have an impact on the external image of the family business. In the financing process, the creditor will use the risk of the family business as the main evaluation factor when setting interest parameters for the family business. The family business with better social responsibility has obvious advantages in dealing with business risks, so creditors will appropriately reduce the interest parameter standards of such family enterprises. In addition, social activities have obvious low-yield or no-revenue characteristics ${ }^{[7]}$. Therefore, when a family business invests more money and energy in social activities, its investment activities will have a negative net present value, which in turn will lead to an increase in business risk. Under this circumstance, the creditor will appropriately increase the interest parameters of the family business out of the judgment of the business risk, which will lead to an increase in the financing cost of the family business. Based on this, hypothesis 2 is proposed:

$\mathrm{H} 2$ : The relationship between family business social responsibility and corporate financing costs is U-shaped.

\section{Research Design}

\subsection{Variable design}

In the analysis of family business social responsibility and corporate financing costs, the variable parameters involved mainly include the following:

First, the social responsibility variable. In terms of this variable, in order to complete the quantitative analysis of family business social responsibility and corporate financing costs, the social contribution parameter per share is taken as the unit of measurement of social responsibility variables. The factors that can affect the value of this unit of measurement are shown in Table 2. Through the analysis of the actual business situation of the family business and the change of social responsibility, the quantitative calculation steps of the social contribution parameters per share can be determined as the following steps: First, the difference between the earnings per share of the family business and the social cost is obtained; Secondly, the expenses incurred by the family business for sponsorship and public welfare activities are added together with the employee's payment and the interest payment cash, and the results are added together with the values in the first step. Finally, the above parameters are subtracted from the social cost, and then the numerator is divided by the average number of ordinary shares issued by the family business, and the income is the social contribution value per share of the family business.

Second, the corporate financing cost variable. Through the analysis of the past financing activities of family enterprises in China, it can be determined that the calculation method of the financing cost variable of the family enterprise is: the ratio of the interest expenditure parameter of the family enterprise used for financing activities to the total debt parameter. Third, control variables. Total variables are shown in table3.

Table 2 Factors of influence contribution per share of family firms

\begin{tabular}{lc}
\hline Main factors & Expected relation \\
\hline Social cost & Negative \\
Donation cost & Positive \\
Earnings per share & Positive \\
Tax return & Negative \\
\hline
\end{tabular}


Table 3 Variables Definition

\begin{tabular}{llll}
\hline & Name & Symbol & Definition \\
\hline $\begin{array}{l}\text { Independent } \\
\text { Variables }\end{array}$ & $\begin{array}{l}\text { Social responsibility of family } \\
\text { firm }\end{array}$ & CSR & $\begin{array}{l}\text { Family firm responsibility to } \\
\text { stakeholders }\end{array}$ \\
Variables & Cost of financing & CF & Return of finance supported \\
& Industry effect & Ind & Dummy variables \\
& Size of firm & SIZE & LN total assets \\
Control & Earnings level of firm & ROA & Return of assets \\
Variables & Leverage & LEV & Leverage of family firm \\
& Growing ability & GROW & Growing rate of main operation \\
& Year & Year & Dummy variable \\
\hline
\end{tabular}

\subsection{Data source and sample selection}

In order to ensure the accuracy of the analysis results, the listed family business financial data information query system is used as the source of the research data. Throughout the research process, SPSS20.0 and EXCEL were used to process and analyze the financial data of each family business. The family business of Shanghai Stock Exchange A shares in 2014-2016 is taken as the initial sample of the study. After the initial sample identification is completed, the family business with the missing value of the variable value is first deleted from the sample; then the family business of the insurance company and the financial enterprise is deleted from the sample; and finally, within the selected time period.

Family businesses that experienced delisting changes or new listing changes were removed from the initial sample ${ }^{[8]}$. After the above process, 517 samples of family business research were obtained in this study.

\subsection{Model design}

The model of family business social responsibility and enterprise financing cost are designed as follows to test hypothesis 1 and hypothesis 2 :

$$
\begin{aligned}
& \mathrm{CF}=\alpha_{1}+\beta_{2} \mathrm{CSR}+\beta_{3} \mathrm{CSRV}^{2}+\beta_{4} \mathrm{SIZE}+\beta_{5} \mathrm{LEV}+\beta_{6} \mathrm{ROA}+\beta_{7} \mathrm{GROW}+\mathrm{IND}+\mathrm{YEAR}+\boldsymbol{\varepsilon} \\
& \mathrm{CF}=\alpha_{1}+\beta_{2} \mathrm{CSR}+\beta_{3} \mathrm{SIZE}+\beta_{4} \mathrm{LEV}+\beta_{5} \mathrm{ROAE}+\beta_{6} \mathrm{GROW}+\mathrm{IND}+\mathrm{YEAR}+\boldsymbol{\varepsilon}
\end{aligned}
$$

\section{The analysis of empirical results}

\subsection{Descriptive analysis}

The descriptive analysis results of family business social responsibility and corporate financing costs are shown in Table 4. For the above 517 family business samples, the maximum and minimum values of their social responsibility variables and financing cost variables are $8.15,-0.87$, and $0.21,0.01$, respectively.

Table 4 Statistics analysis

\begin{tabular}{llllll}
\hline Variables & Number & Standard error & Average & Maximum & Minimum \\
\hline CSR & 517 & 0.01 & 1.24 & 8.15 & -0.87 \\
CF & 517 & 1.54 & 0.04 & 0.21 & 0.01 \\
Ind & 517 & 0.83 & 0.13 & 1 & 0 \\
SIZE & 517 & 1.11 & 13.69 & 25.81 & 17.65 \\
ROA & 517 & 0.03 & 0.05 & 0.05 & -0.77 \\
LEV & 517 & 0.09 & 0.51 & 0.53 & 0.07 \\
GROW & 517 & 20.15 & 17.32 & 18.11 & -75.28 \\
\hline
\end{tabular}




\subsection{Correlation analysis}

In order to determine the correlation between the corporate social responsibility of the research object family and the financing cost of the enterprise, the relevant financial data is used to analyze all the research objects.

Table 5 Correlation analysis

\begin{tabular}{llllllll}
\hline & CSR & CF & IND & SIZE & ROA & LEV & GROW \\
\hline CSR & 1 & & & & & & \\
CF & $-0.075 *$ & 1 & & & & & \\
Ind & -0.026 & 0.035 & 1 & & & & \\
SIZE & $-0.109 * *$ & $0.291 * *$ & $0.103 *$ & 1 & & & \\
ROA & $0.092 *$ & $0.135 * *$ & 0.215 & $0.315 *$ & 1 & & \\
LEV & $0.357 * *$ & $0.083 * *$ & 0.301 & $0.085 * *$ & $0.015 *$ & 1 & \\
GROW & $-0.199 *$ & $0.077 * *$ & $0.019 *$ & $0.033 *$ & $0.036 *$ & $0.057 * *$ & 1 \\
\hline
\end{tabular}

\subsection{Regression analysis}

Before the regression analysis of the social responsibility variables of the family business and the enterprise financing cost variables, it is judged in advance whether the two variables can be subjected to regression analysis by means of the homogeneity test of variance. The homogeneity test results of variance show that regression analysis can be performed on these two variables. The results of the one-factor homogeneity test between the corporate social responsibility and the financing cost of the research object family are shown in Table 6.

Table 6 Single factor homogeneity test

\begin{tabular}{llll}
\hline Standard level & Sig. & df1 & df2 \\
\hline \multicolumn{1}{c}{0.305} & 5 & 119 \\
\hline \multicolumn{5}{c}{ Table 7 Multiple regression results } \\
\hline Constant & Unstardarized error B & Sig. \\
CSR & 0.110 & 0.000 \\
ROA & -0.106 & 9.721 \\
GROW & -0.001 & 0.098 \\
SIZE & -0.017 & 0.032 \\
LEV & -0.732 & 0.068 \\
\hline
\end{tabular}

The test results show that there is a significant difference between the financing costs of the financial data of the analyzed subjects. This result shows that with the changes in the level of social responsibility development of family businesses, the financing costs required for family businesses to carry out financing activities will also change. The regression analysis results of each variable are shown in Table 7. As can be seen from Table 7, the regression coefficient of the social responsibility CSR of the family business is -0.106 , which is significant at the 0.05 level. This phenomenon indicates that hypothesis 1 is established. However, the regression coefficient of $\mathrm{CSR}^{2}$ is not significant at the 0.05 level, so it can be considered that hypothesis 2 does not hold.

\section{Robustness test}

\subsection{Reliability test}

In order to ensure the accuracy of the above research results, the results are analyzed here using reliability. The test results show that the reliability of the assumption that the family business of the research family increases with the increase of the social responsibility level is 0.847 . This result shows that the degree of credibility between the level of social responsibility and the cost of financing is extremely high. 


\subsection{Validity test and consistency test}

In order to better analyze the relationship between family business social responsibility and financing costs, two different assumptions were made for these two factors. The results of the validity test and the consistency test show that the validity of the first hypothesis is low, and the second half of the U-shaped relationship (positive correlation) does not hold; the validity of the second hypothesis is high, the consistency test result the correctness of this assumption is verified. The control variable of industry size is separated as the main analytical variable. Through the analysis of the stability test of family business social responsibility and financing cost under the influence of this variable, it can be found that the scale of family business and the use of social responsibility level control financing The relationship between the realization of the cost objectives is a negative correlation, that is, the second hypothesis is established.

\section{Research conclusions and related recommendations}

\subsection{Research summary}

According to the above analysis process, the following conclusions can be drawn:

First, there is a significant correlation between the social responsibility of the research family business and the cost of corporate finance, and this correlation is negatively related: that is, as the level of social responsibility of the family business continues to increase, it is spent on financing activities. The financing cost parameter is gradually reduced. Hypothesis 1 does not hold. From a theoretical perspective, as family businesses invest more in social activities, creditors' judgments on their ability to cope with risks should change accordingly. It can be inferred that the reason why Hypothesis 1 is not established is that the current level of social activity investment of family enterprises in China is relatively low, and the funds for charitable activities donation and sponsorship expenses are far lower than the standards for generating negative net present value. Therefore, the creditor's assessment and judgment of the family business's ability to manage and respond to risks will not change significantly. Therefore, there is always a negative correlation between the social responsibility of the family business and the financing cost in this study ${ }^{[9]}$.

Second, the relationship between the size of the family business and the family business's use of improving the level of development of its own social responsibility to achieve the goal of controlling financing costs is negatively correlated. Namely: With the continuous increase of the size of the family business, it is more and more difficult to achieve the goal of reducing the financing cost by improving the level of social responsibility development. The results of this study are completely consistent with the theoretical analysis

\subsection{Suggestions}

\subsubsection{Improve management's awareness of fulfilling social responsibility}

Based on the above research, the overall development level of corporate social responsibility of the research target family is relatively low. Therefore, in order to promote the benign development of family businesses and enhance their social benefits, it is necessary to raise the awareness of family business management to fulfill their social responsibilities as an important task. In order to achieve this goal, the awareness of family business management personnel can be optimized in the following ways:

First, the training method. The advent of the era of knowledge has led to a significant increase in the importance of knowledge and culture. In this context, the number of training courses in China has also increased significantly. Because the senior management of the family business is not professional in training, it can cooperate with the excellent training institutions of the city's excellent management personnel. The training institutions provide courses and teachers to meet the training needs of the family enterprises, and then enhance Management personnel fulfill the purpose of social responsibility awareness ${ }^{[10]}$. On the other hand, family businesses can allocate a certain amount of time according to the schedule of their own management staff, transfer their management personnel to the training institutions, and provide more professional enterprise training seminars for trainees. 
This kind of win-win cooperation can transform the behavior of family enterprises to enhance the management's awareness of social responsibility into a long-term mechanism, laying the foundation for the continuous growth of family business social responsibility.

Second, the way of cooperation and exchange between family businesses. In addition to external forces, the internal strength of family businesses is also an important way to optimize management personnel's awareness of social responsibility. The competitive nature of the market makes it impossible to maintain a harmonious relationship between family businesses in the same industry. Therefore, cooperation and exchange work can be carried out between family businesses in different industries. In order to enhance the enthusiasm of family businesses to participate in cooperation and exchange activities, in the process of selecting a family business, there should be a certain relationship in the business process, but family businesses that are not in the same field form different cooperation and exchange groups. In the process of cooperation and exchange, these family-owned enterprises can acquire the corresponding experience through the promotion of social responsibility methods and concepts of other enterprises, and may also establish a good cooperative relationship with each other, and enhance the combination of the two based on communication to enhance the development of social responsibility. The relationship rose to the height of the partner . At this level, the exchanges between the two about raising awareness of the social responsibility of management personnel will become deeper and unreserved.

\subsubsection{Improve performance appraisal mechanism and reward and punishment measures}

Psychology believes that the provision or change of motivation makes it easier for individuals to make some changes. Based on this principle, in the process of perfecting the employee management system of family enterprises, the reward and punishment system that family businesses can be related to the development of social responsibility is integrated into the original management system. For employees, the application of incentives fully motivates their interest in social responsibility and participation in social activities. Under the influence of this kind of power, they are more likely to create greater value for the promotion and development of family business social responsibility; in addition, the inclusion of punitive measures in the family business management system can greatly reduce employees' non-compliance with social responsibility behaviors. occur. In order to improve the performance of employees in fulfilling the status quo of social responsibility behavior, we can combine the perfect performance appraisal with the application punishment system.

\subsubsection{Strengthening the construction of internal and external supervision and management} mechanisms

From an essential point of view, the fulfillment of employee social responsibility will be affected and affected by some factors. In order to keep the interference and impact of these factors at the lowest level, the family business can construct corresponding supervision and management mechanisms from the following aspects, so as to have a good constraint and normative effect on employees.

First, the internal aspect. Based on the implementation of social responsibility and the promotion of social responsibility development management supervision system. In addition to the normal management system such as employee work practices, family businesses can construct an independent management and supervision system specifically for social responsibility . For example, the contribution of employees to the development of family business social responsibility can be expressed in points: each employee has 300 initial points. When employees have a positive impact on family business social responsibility, the employee's points are appropriately increased according to the degree of influence; when the employee has a negative impact on social responsibility, the employee's certain points are appropriately deducted. With quarterly settlement standards, if an employee's share of the increase in points in a quarter can reach $10 \%$, the salary can also increase by $10 \%$ in the next month; similarly, if the employee's social responsibility score falls by more than $10 \%$, then Its wages will also decline year on year.

Second, the external aspect. External supervision of family business social responsibility needs to be done with the help of social forces. For example, a family business can cooperate with a public welfare agency, and the public welfare agency is responsible for publicizing the contribution of the family business to the public welfare activity at a certain time interval. In this model, the charity 
organization and the people from all walks of life form a supervision group to supervise the public welfare behavior of the family business; the responsibility of the family business is to fully understand the increase in the proportion of social activities and the negative net present value. The threshold between. Taking this threshold as the input standard, it will use itself to fulfill the social investment and material input control under the standard, and prevent the creditor's assessment of its risk response ability from adversely changing the level of social responsibility development .

6.2.4. Improve the evaluation mechanism of family business financing activities

In order to achieve the goal of reducing financing costs, family businesses should not only promote the development of their own social responsibilities, but also build a more comprehensive financing activity evaluation mechanism based on the process of assessing their risk response capabilities. From a theoretical perspective, when the social responsibility of a family business reaches a certain level, although it will produce a negative net present value, it does not mean that its risk response ability will be reduced. In order for creditors to raise interest rates to influence the enthusiasm of family businesses to participate in social activities, more factors that reflect the family business risk response capabilities should be integrated into the financing activity evaluation mechanism. For example, family business history management risk solving ability, quality of resolution, etc. For family businesses, the application of improved financing activity assessment mechanism can more fully demonstrate the family business's operational capabilities, risk prediction and processing capabilities.

\section{Acknowledgement}

This paper is supported by National Social Science Fund (13AZD002) and Jilin University of Finance and Economics project "Regional Tourism Culture Research in Jilin Province" (2016P41).

\section{Reference}

[1] Jeremy Galbreath, Drivers of corporate social responsibility: the role of formal strategic planning and firm culture, British of Journal of Management, vol.21,511-525(2010).

[2] Lei Wang, Heikki Jusin, The impact of Chinese culture on corporate social responsibility: the Harmony Approach, Journal of business ethic, (2009)88:433-451.

[3] Mc Guire, S. T. , T C. Omer, and N. Y. Sharp, 2012, "The Impact of Religion on Financial Reporting Irregularities”, Accounting Review, 87( 2) : 645-673. 2012.

[4] Schouten C M-V D D, Graafland J, Kaptein M. Religiosity, CSR Attitudes, and CSR Behavior: An Empirical Study of Executives' Religiosity and CSR [J] . Journal of Business Ethics, 2014, 123 (3) : 437-459.

[5] Walker A G, Smither J W, Debode J. The Effects of Religiosity on Ethical Judgments [J] . Journal of Business Ethics, 2012, 106 (4) : 437-452.

[6] Yin J, Zhang Y. Institutional dynamics and corporate social responsibility ( CSR ) in an emerging country context : Evidence from China $[\mathbf{J}]$. Journal of Business Ethics , 2012, 111(2): $301-316$.

[7] Bai Y. and Kung J., 2014, "Does Genetic Distance Have a Barrier Effect on Technology Diffusion? Evidence from Historical China”, Hong Kong University of Science and Technology, Working Paper.

[8] Carroll, A.B., 1979, “A Three- Dimensional Conceptual Model of Corporate Performance”, Academy of Management Review, Vol. 4, pp.497 505. 
[9] Shleifer, A., and Vishny, R., W., 1997, "Legal Determinants of External Finance" [J], Journal of Finance, Vol.52,3, PP1131-1150.

[10]Cormier D,Magnan E. The informational contribution of social and environmental disclosures for investors [J], Management Decision,2011, 49(8);1276-1304. 